\title{
AnthracnoseTracer: A Spatiotemporal Model for Simulating the Spread of Anthracnose in a Lupin Field
}

\author{
A. J. Diggle, M. U. Salam, G. J. Thomas, H. A. Yang, M. O’Connell, and M. W. Sweetingham
}

First, third, fifth, and sixth authors: Department of Agriculture-Western Australia, 3 Baron-Hay Court, South Perth, WA 6151, Australia; second author: Centre for Cropping Systems, Department of Agriculture-Western Australia, Lot 12 (P.O. Box 483), Northam, WA 6401, Australia; and first, third, fourth, and fifth authors: Co-operative Research Centre for Legumes in Mediterranean Agriculture, The University of Western Australia, Crawley, WA 6009, Australia.

Accepted for publication 15 May 2002.

\begin{abstract}
Diggle, A. J., Salam, M. U., Thomas, G. J., Yang, H. A., O’Connell, M., and Sweetingham, M. W. 2002. AnthracnoseTracer: A spatiotemporal model for simulating the spread of anthracnose in a lupin field. Phytopathology 92:1110-1121.

A spatiotemporal model has been developed to simulate the spread of anthracnose, initiated by infected seed, in a lupin field. The model quantifies the loss of healthy growing points of lupin in all $1-\mathrm{m}^{2}$ subunits of a field throughout a growing season. The development of growing points is modeled as a function of temperature using a 1-day time step,

traveled by spores is partially dependent on wind speed and is generated by adding the values selected from half-Cauchy distributions. The direction of travel of the spores is influenced by wind direction. The model has been employed to produce a theoretical assessment of damage from disease in two environments at five levels of seed infection. It was calculated that in a susceptible lupin cultivar with a $0.01 \%$ initial seed infection, anthracnose would cause approximately $15 \%$ loss of healthy growing points in a high rainfall environment in Western Australia. In a low rainfall environment, similar damage would be unlikely even with a much higher $(1 \%)$ level of seed infection.
\end{abstract} and disease-induced compensatory growth is accounted for. Dispersal of spores is simulated explicitly using Monte Carlo techniques. Spread of spores occurs during rainfall events on a 1-h time step. The distance

Anthracnose, caused by Colletotrichum gloeosporioides (Penz.) Penz. \& Sacc., is considered to be the most devastating disease of lupin (31). It has been reported in almost all the lupin growing regions of the world $(7,20,23,24,31,32,44)$ and in all of the species of commercial crops (Lupinus angustifolius L., L. luteus, L. albus L., and L. mutabilis), ornamentals (L. polyphyllus), and perennials (L. arboreus) $(24,33,47)$. Prior to 1996 , the disease had not been found in crops in Australia (37,39), which is the world's largest producer of lupin grain. However, during 1996, major outbreaks of anthracnose were reported in several lupin crops in the northern agricultural region of Western Australia (40). Since then, anthracnose has spread rapidly through the high rainfall and warmer agricultural areas, with pockets of low level infection through other parts of the agricultural areas of Western Australia (36). However, it is not present in large areas of lupin production in Victoria and New South Wales (24). The modeling and experimental work presented here has contributed to the formulation of strategies for management of lupin anthracnose in Western Australia in areas where it is already found and has been used to predict its potential to cause damage in the regions where it has not yet spread.

Simulating spread of any plant disease requires integration of environmental data with details of the infection processes and epidemiology of the disease. Mathematical formulations have been proposed to describe movement of plant pathogens in two dimensions $(35,49)$ and radially $(25)$. Using these approaches, a number of theoretical plant disease spread models have been developed $(27,29,46)$. Recently, Aylor (2) and Jeger (21) have reviewed the

Corresponding author: M. U. Salam; E-mail address: msalam@agric.wa.gov.au

Publication no. P-2002-0819-01R

(C) 2002 The American Phytopathological Society
Additional keywords: growing point loss, quantitative epidemiology, spread of diseases.

current status of research, including modeling, of aerial dispersal of pests and pathogens. A number of spatially based models have been developed and tested for specific diseases, for example, apple scab (1), bean rust (3), citrus tristeza virus (28), cocoa swollen shoot (22), potato late blight (16), and tobacco blue mold (4). For anthracnose, models have been developed for a number of hosts, e.g., citrus (41), mango (14), shrubby stylo, Stylosanthes scabra $(38,45)$, strawberry $(27,48)$, and watermelon $(30)$. To our knowledge, there is no such model published for lupin.

Many of the already developed anthracnose models are essentially regression models $(14,30,41)$ and are nonmechanistic in nature. The strawberry-anthracnose model (48) concentrates mainly on rain-splash characteristics for pathogen dispersion. For simulating anthracnose in shrubby stylo, Smyth et al. (38) used their field experimental data to develop a stochastic Markov chain model. The model described both spatial and temporal aspects of anthracnose progression. However, to adapt this model for different species or environment, as a characteristic of Markov process (15), a large number of measurements would be needed for approximation of the parameters.

For modeling the spread of anthracnose in lupin, a key consideration is that initial infection comes from the fungal spores or mycelia carried on or in the seed. Seedlings from infected seed develop cotyledon and hypocotyl lesions, which produce an abundance of spores (conidia) that are spread through the crop by rainsplashed droplets. Under field condition, characteristic symptoms of anthracnose infection lesions appear on petioles, stems, and pods. Stem tissue (the first internode) immediately below the growing point is the most susceptible to infection and this is where most lesions are initiated. Older internodes are much more resistant to infection (H. A. Yang and M. W. Sweetingham, unpublished data). Lupin plants continuously develop growing points (terminal and lateral shoot apices, branches, inflorescence, 
and flowers) throughout the growing period. Simulation of growing point dynamics is, thus, crucial for capturing spread of anthracnose in lupins. Wilson and Chakraborty (45) found a similar situation in the case of anthracnose of shrubby stylo where stem lesions often lead to terminal death of the apical meristem. Furthermore, Madden et al. (26) indicated that yield or population compensation is evident in some systems where yield or loss of a plant or plant parts depends on the status of the neighboring plants $(18,19,34)$. Lupins belong to such a system $(10)$.

Lupin anthracnose is a seedborne disease (39), and infected seed is the primary source of inoculum in most crops. Very low levels of seed infection can lead to serious crop infection, and Gondran and Pacault (17) recommend that seed testing be able to detect seed infection as low as $0.01 \%$.

Two factors that influence the spread of anthracnose within a lupin crop are seasonal rainfall (anthracnose is spread by rainsplash of spores) and varietal resistance. These two factors determine the effect that given levels of seed infection have on disease development and yield loss. In Western Australia, there are significant variations of seasonal rainfall between agricultural regions and between species and cultivars in resistance to anthracnose (5). Because of the rapid establishment and spread of anthracnose in Western Australia, farmers require information on likely interactions between seasonal rainfall, cultivar choice, and level of infection in sown seed. In order to estimate how anthracnose will affect crops in areas where the disease has not yet occurred, a model is required.

Considering the above, we have developed a spatiotemporal model for lupin anthracnose that simulates the spread of anthracnose in a field over a growing season. The aims of this study are to (i) describe the model, (ii) test the model with observed disease incidence in three lupin cultivars of different anthracnose resistance, and (iii) apply the model for two climatic scenarios assessing the extent of the disease that develops from different initial levels of seed infection.

\section{THEORY AND APPROACHES}

AnthracnoseTracer: the simulation model. AnthrancoseTracer divides a field into equal-sized small rectangular cells termed subunits. Crop growth and pathogenic activities are simulated individually in each subunit. Crop growth, in the model, is an intrasubunit phenomenon, whereas the pathogenic activities occur both within and between subunits. Crop growth is described in terms of development of growing points. There is initially one growing point per sown seed. The growing points multiply at a rate that is a function of temperature and is limited by proximity to a maximum growing point density. Simulation of disease initiation and its subsequent development and dispersal are based on the factors and processes outlined in Figure 1. Infected seed is the primary source of infection, producing infected growing points on the seedlings at emergence. Infected growing points upon completion of a latent period become sporulating. The length of the latent period is a function of temperature (Table 1). The number of spores produced by a sporulating growing point depends on the level of disease resistance of the cultivar. Spores can spread by rain-splashed deposits from sporulating to uninfected growing points whenever a threshold of rainfall has been exceeded. The rainfall threshold describes the quantity of rainfall required for

TABLE 1. Time from inoculation until development of sporulating lesions of Colletotrichum gloeosporiodes in lupin (cv. Kiev Mutant) at three different temperatures under five leaf wetness periods

\begin{tabular}{lccc}
\hline \multirow{2}{*}{$\begin{array}{l}\text { Leaf wetness period after } \\
\text { incubation (hours) }\end{array}$} & \multicolumn{2}{c}{ Days to sporulation at temperature $\left({ }^{\circ} \mathrm{C}\right)$} \\
\cline { 2 - 4 } 4 & 12 & 18 & 24 \\
6 & 17 & 8 & 7 \\
9 & 15 & 8 & 7 \\
12 & 14 & 8 & 6 \\
24 & 13 & 7 & 6 \\
\hline
\end{tabular}

Plant Infection Process

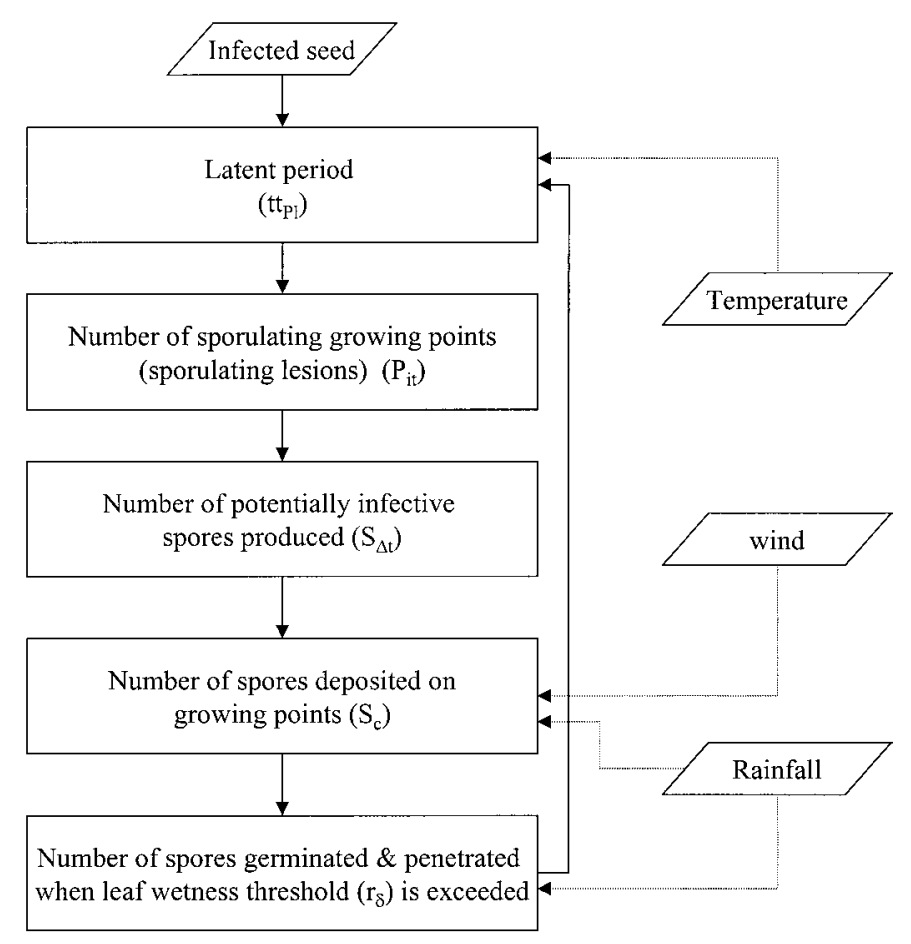

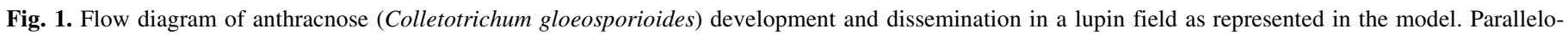

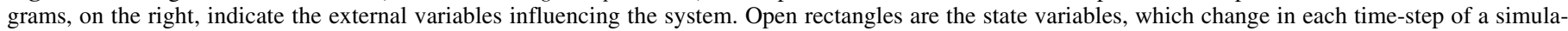
tion. Arrows with solid lines indicate flow of material, and arrows with broken lines show flow of information. 
dispersal, and to produce duration of leaf-wetness sufficient for germination and penetration of spores (8). Wind speed and direction influence the distance of spore dispersal during rain events.

The model is written in Mathematica (version 4.0, Wolfram Research, Champaign, IL). The functions in the model that control developments of growing points, and those that govern production and interception of spores, have been developed from the literature and from limited experimentation. The spore dispersal function is an adaptation from Shaw (35) and $\mathrm{Xu}$ and Ridout (46).

Model algorithms. The algorithms used in the model can broadly be divided into the host-related processes of growth and development of growing points and the pathogen-related processes of spore production, dispersal, and deposition (Table 2 provides description of the symbols). The number of new growing points $\left(P_{h n \Delta t}\right)$ in an iteration period of 1 day, $\Delta t$, is calculated as

$$
P_{h n \Delta t}=P_{h t} \times R_{P h} \times T\left(1-P_{h t} / P_{h m}\right)
$$

where $P_{\mathrm{ht}}$ is the total number of healthy growing points at time $t, t$ is the time immediately before $\Delta t$, and $T$ is the average daily

TABLE 2. Description of symbols used in the algorithms of the model AnthracnoseTracer

\begin{tabular}{ll}
\hline Symbol & Description \\
\hline$D$ & Displacement vector \\
$F$ & A proportion \\
$K$ & A dimentionless parameter \\
$N$ & Whole plant \\
$P$ & Growing point \\
$R$ & Replication rate \\
$S$ & Spore \\
$T$ & Average daily temperature \\
$V$ & Period when a new growing point is susceptible to infection \\
$X$ & A reference subunit that remains free from infection \\
$b$ & Base temperature in relation to thermal time \\
$c$ & Probability of interception \\
$d$ & Displacement distance \\
$h$ & Healthy \\
$i$ & Infective \\
$l$ & Latent \\
$m$ & Maximum \\
$n$ & New \\
$r$ & Refers to rain \\
$t$ & A point in time \\
$\mathrm{tt}$ & Thermal time \\
$w$ & Refers to wind \\
$z$ & Uniform random number between 0 and 1 \\
$\Delta$ & Interval \\
$\delta$ & Threshold \\
$\mu$ & Dispersal distance parameter \\
$\theta$ & Displacement angle \\
\hline & \\
\hline &
\end{tabular}

temperature in degree Celsius. $R_{P h}$ and $P_{h m}$ are the replication rate of the growing points and maximum number of growing points in a unit area, respectively. The parameter $R_{P h}$ is defined as the rate of increase of number of growing points per degree Celsius per day (Table 3). The number of healthy or uninfective growing points at the end of the iteration period $\left(P_{h t+\Delta t}\right)$ is the sum of $P_{h t}$ and $P_{h n \Delta t}$ less the number of infective (sporulating) growing points $\left(P_{i \Delta t}\right)$ that appear in $\Delta t$.

$$
P_{h t+\Delta t}=P_{h t}+P_{h n \Delta t}-P_{i \Delta t}
$$

Dispersal of spores in the model is calculated in terms of potentially infective spores. The novel concept of potentially infective spores integrates the number of spores produced per sporulating growing point over the infective or sporulation period, and the probability for each spore that will produce an infection under suitable environmental conditions. Spores are spread from each subunit in each hour where rainfall exceeds the threshold, $r_{\delta}$ (Table 3). The rainfall threshold has not been determined experimentally but has been taken to be $2 \mathrm{~mm}$ in a day and $0.1 \mathrm{~mm}$ in a wet-hour under Western Australian conditions, which we estimate will provide an adequate period of leaf wetness (greater than $4 \mathrm{~h}$ ) (Table 1). The number of potentially infective spores $\left(S_{\Delta t}\right)$ spread from a subunit during a wet-hour is linearly related to the total number of sporulating growing points present at time $t\left(P_{i t}\right)$ in that subunit. The model does not consider in detail the mechanism of lesion formation or its dynamism. Rather, it employs the simplified concept of a sporulating growing point or sporulating lesion, which is a growing point where an infective spore has caused an infection and the infection has passed a latent period. The number of potentially infective spores produced per sporulating growing point (or sporulating lesion) $\left(S_{P i}\right)$ is assumed to be constant, implying that a sporulating growing point produces spores at a constant rate after formation. Consequently, $S_{P i}$ is a simple multiplicative factor on $P_{i t}$ in the calculation of $S_{\Delta t}$. Many simulation models use a similar simplifying assumption, as indicated by van der Plank (42).

$$
S_{\Delta t} \sim \text { Poisson }\left(S_{P i} \times P_{i t}\right)
$$

$S_{\Delta t}$ is a random integer value chosen from a Poisson distribution using the expected number of spores during that period, which is a fractional value. Not all the potentially infective spores produce infections because the density of receptive growing points in the target area is often less than optimal. In the model, the spore deposition probability $\left(S_{c}\right)$ is used to convert potentially infective spores to number of successful infections. The deposition prob-

\begin{tabular}{|c|c|c|c|c|}
\hline Parameter & Description & Unit & Equation & Value \\
\hline$\mu_{S r}$ & Median spore dispersal distance parameter of the half-Cauchy distribution in relation to rain splash & $\mathrm{m}$ & 7 & 0.50 \\
\hline$\mu_{S w}$ & Median spore dispersal distance parameter of the half-Cauchy distribution in relation to wind & $\mathrm{m}$ & 7 & 0.10 \\
\hline$K_{S c}$ & $\begin{array}{l}\text { Spore deposition parameter indicating the limit of probability of deposition of a spore on a } \\
\text { susceptible growing point }\end{array}$ & $\mathrm{S}^{-1} \mathrm{P}^{-1} \mathrm{~m}^{-2}$ & 4 & 0.0026 \\
\hline$P_{h m}$ & Maximum growing point density & $\mathrm{P} \mathrm{m}^{-2}$ & 1 & 15,000 \\
\hline$r_{\delta}$ & $\begin{array}{l}\text { Rainfall threshold indicating the minimum amount of rainfall required in a wet-hour for germination } \\
\text { and successful penetration of spores. This is true when a day receives total rainfall of over } 2 \mathrm{~mm}\end{array}$ & mm wet-hour ${ }^{-1}$ & - & 0.1 \\
\hline$R_{P h}$ & Replication rate of growing points & $\mathrm{P} \mathrm{m}^{-2}\left({ }^{\circ} \mathrm{C} / \text { day }\right)^{-1}$ & 1 & 0.0065 \\
\hline$V$ & The duration for which when a new growing point is susceptible to infection & Day & 4 & 5 \\
\hline$T_{b}$ & Base temperature for spore growth & ${ }^{\circ} \mathrm{C}$ & 5 & 0 \\
\hline$t t_{P l m}$ & Thermal time during which infective growing points remain in latent phase & ${ }^{\circ} \mathrm{C} /$ day & - & 200 \\
\hline
\end{tabular}
ability is calculated using an exponential function similar to that

TABLE 3. List of parameters and their values used in the model AnthracnoseTracer 
commonly used for estimating the fraction of the incoming radiation intercepted by a crop canopy (43).

$$
S_{c}=1-\exp \left(-K_{S c} \times P_{h n \Delta t} \times V\right)
$$

$K_{S c}$ is the limit of the probability of deposition of potentially infective spores on susceptible growing points in a square meter area as the density of susceptible growing points $\left(P_{h n \Delta t} \times V\right)$ approaches 0 . New growing points remain susceptible to infection for a period, $V$ (in days), from their time of initiation. Based on qualitative field observations, we have assumed a 5-day period of susceptibility. The number of susceptible growing points on each day is approximated as the product of the period of susceptibility and the number of growing points formed on that day $\left(P_{h n \Delta t}\right)$. The infected growing points become sporulating growing points after completing a latent period $\left(t t_{P l m}\right)$ of 200 degree-days (Table 1). The model calculates accumulated degree-days in each day for each infected but latent growing point $\left(t t_{P l}\right)$ using a base temperature $\left(T_{b}\right)$.

$$
t t_{P l}=\sum\left(T-T_{b}\right)
$$

Spores are spread independently from each of the subunits that contain sporulating lesions. Dispersal of each potentially infective spore $\left(D_{S}\left(\theta_{S}, d_{S}\right)\right)$ is a displacement vector with angle $\left(\theta_{S}\right)$ and distance $\left(d_{S}\right)$ components. This vector specifies the location where the spore lands relative to its starting point. The actual dispersal is the vector sum of dispersal due to rain splash $\left(D_{S r}\left(\theta_{S r}, d_{S r}\right)\right)$ and dispersal due to wind $\left(D_{S w}\left(\theta_{S w}, d_{S w}\right)\right)$ :

$$
D_{S}\left(\theta_{S}, d_{S}\right)=D_{S r}\left(\theta_{S r}, d_{S r}\right)+D_{S w}\left(\theta_{S w}, d_{S w}\right)
$$

The angle of dispersal due to rain splash $\left(\theta_{S r}\right)$ is a random number, with uniform probability from 0 to $360^{\circ}$. Wind-induced dispersal angle $\left(\theta_{S w}\right)$ is chosen from a normal distribution defined by the average wind direction $\left(^{\circ}\right)$ in the hour and the standard deviation of wind direction as measured by a recording weather station that measures wind direction at $10-\mathrm{s}$ interval. The distance component of dispersal due to rain splash ( $d_{S r}$ in meters) is a

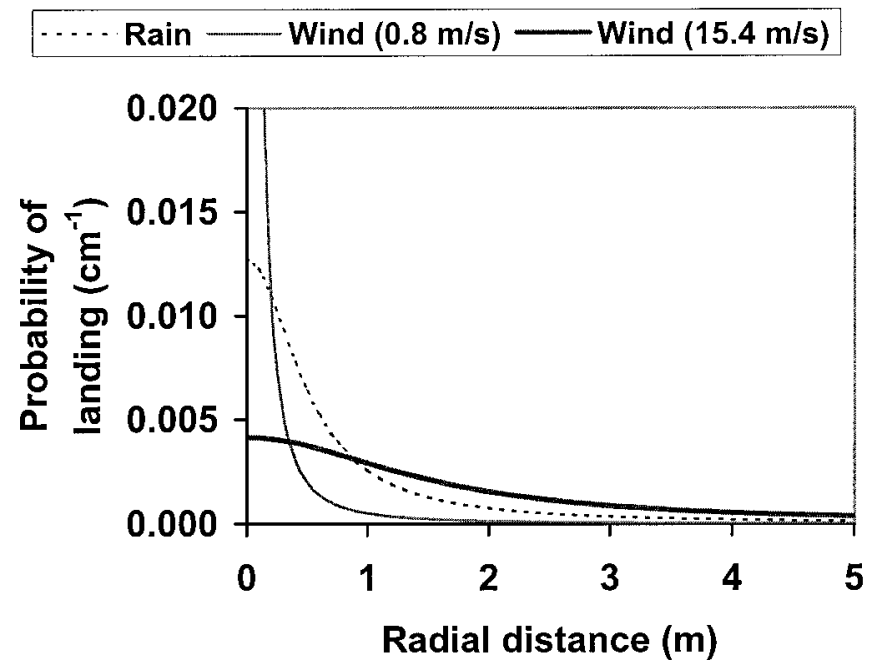

Fig. 2. Probability of spores landing versus radial distance (equation 7) for the components of spread due to rain-splash $\left(\mu_{S r}=0.5\right)$ and wind at two velocities, 0.8 and $15.4 \mathrm{~m} / \mathrm{s}\left(\mu_{S w}=0.1\right)$. random value chosen from a half-Cauchy distribution $(35,46)$ with median dispersal parameter $\mu_{S r}$ :

$$
d_{S r}=\mu_{S r} \times \tan (\pi \times z / 2)
$$

where $z$ is a uniform random number on the interval between 0 and 1. The median dispersal parameter is the median of the distribution distance in meters that spores may travel. The distance component of dispersal $\left(d_{S w}\right)$ due to wind is calculated in the same way using equation 7 , but the median dispersal parameter $\mu_{S w}$ is multiplied by the average wind speed (meters per second) for the hour. Examples of distributions for the distance component of displacement due to rain splash and due to wind at two extreme wind speeds are shown in Figure 2.

The spore dispersal vectors are considered to originate from the center of the subunit of origin. The spores land in whatever subunit contains the termination point of the vector. The destination subunit may be the same subunit from which a spore has originated, or it may be another subunit within or outside the field. When the destination subunit is located outside the field, the model can be set to either of two options, to ignore it or to wrap it. When wrapping is chosen, the model simulates the equivalent of an infinite area made up of repeated copies of the field. When wrapping is not chosen, the model simulates a finite area isolated from other sources of disease.

Parameterization, initialization, input, and output. Parameters and their values used in the model are listed in Table 3. Table 4 shows inputs and initialization variables. The maximum growing point density $\left(P_{h m}\right)$ of a lupin crop was calculated based on the literature $(6,9-13)$ and summarized in Table 5 . The growing point replication rate $\left(R_{P h}\right)$ was determined from a growing point growth curve that was developed based on information from the literature (10). The spore deposition parameter $\left(K_{S c}\right)$, upper limit of the probability of deposition of spores, was chosen so that infections approached the number of potentially infective spores when density of susceptible growing points was at the maximum value ob-

TABLE 4. List of inputs and initialization variables used during calibration and testing and experimenting with the model AnthracnoseTracer

\begin{tabular}{lc}
\hline Input / initialization variable & Value \\
\hline Weather & $\begin{array}{c}\text { Location specific } \\
\text { Weather data }\end{array}$ \\
Mean daily air temperature $\left({ }^{\circ} \mathrm{C}\right)$ & \\
Rain in each hour $(\mathrm{mm} / \mathrm{h})$ & \\
Average wind speed in each wet hour (m/s) & \\
Wind vector direction (degree) & {$[(1,1)]$} \\
Standard deviation of wind direction (degree) & \\
Summary unit size [(m N-S, m E-W)] & {$[(45,8)]$} \\
Field size [(m N-S, $\mathrm{m} \mathrm{E-W)]}$ & {$[(200,80)]$} \\
Calibration and testing & 40 \\
Experimentation & \\
Seeding rate (plants/m $\left.{ }^{2}\right)$ & 140 \\
Start day of simulation (Julian day) & 127 \\
Calibration and testing & 140 \\
Experimentation in Merredin & \\
Experimentation in Geraldton & 313 \\
End day of simulation (Julian day) & 295 \\
Calibration and testing & 313 \\
Experimentation in Merredin & \\
Experimentation in Geraldton & 153 \\
Time of initial infection (Julian day) & 140 \\
Calibration and testing & 153 \\
Experimentation in Merredin & \\
Experimentation in Geraldton & {$[(4,15)(4,30)]$} \\
Location of initial points of infection [(m south, m west)] & Random \\
Calibration and testing & \\
Experimentation & False \\
Wrapping (of dispersing spores) & True \\
Calibration and testing & \\
Experimentation & \\
\hline
\end{tabular}


served in the experiment. The number of potentially infective spores per sporulating growing point $\left(S_{P i}\right)$ differs for the three cultivars depending on their resistance. The value of $S_{P i}$ for cv. Wonga was established through calibration by fitting the model to field observations of anthracnose incidence during early disease development from the field experiment described in the next section. This parameter $\left(S_{P i}\right)$ value for the other cultivars was adjusted relative to the value for cv. Wonga based on counts of spores from lesions on the respective cultivars (G. J. Thomas, unpublished data). The spread parameters $\left(\mu_{S r}\right.$ and $\left.\mu_{S w}\right)$ were also

TABLE 5. Summary of growing points in a typical narrow-leafed lupin plant based on published data (6,9-13)

\begin{tabular}{|c|c|c|c|c|c|c|}
\hline Components & Main shoot & First-order branching & Second-order branching & Third-order branching & Total per plant & Total per area $\left(\mathrm{m}^{2}\right)$ \\
\hline Branch & 1.0 & 20.0 & 7.5 & 7.5 & 36.0 & $1,440.0$ \\
\hline Leaves per branch & 21.0 & 7.0 & 6.0 & 5.0 & 39.0 & $1,560.0$ \\
\hline Total leaves & 21.0 & 140.0 & 45.0 & 37.5 & 243.5 & $9,740.0$ \\
\hline Inflorescence & 1.0 & 3.0 & 4.0 & 1.0 & 9.0 & 360.0 \\
\hline Flowers per inflorescence & 18.8 & 21.4 & 12.0 & 1.8 & 53.9 & $2,157.6$ \\
\hline Total flowers & 18.8 & 64.1 & 48.0 & 1.8 & 132.7 & $5,306.4$ \\
\hline Growing points & 39.8 & 204.1 & 93.0 & 39.3 & 376.2 & $15,046.4$ \\
\hline
\end{tabular}

UNINFECTIVE GROWING POINTS
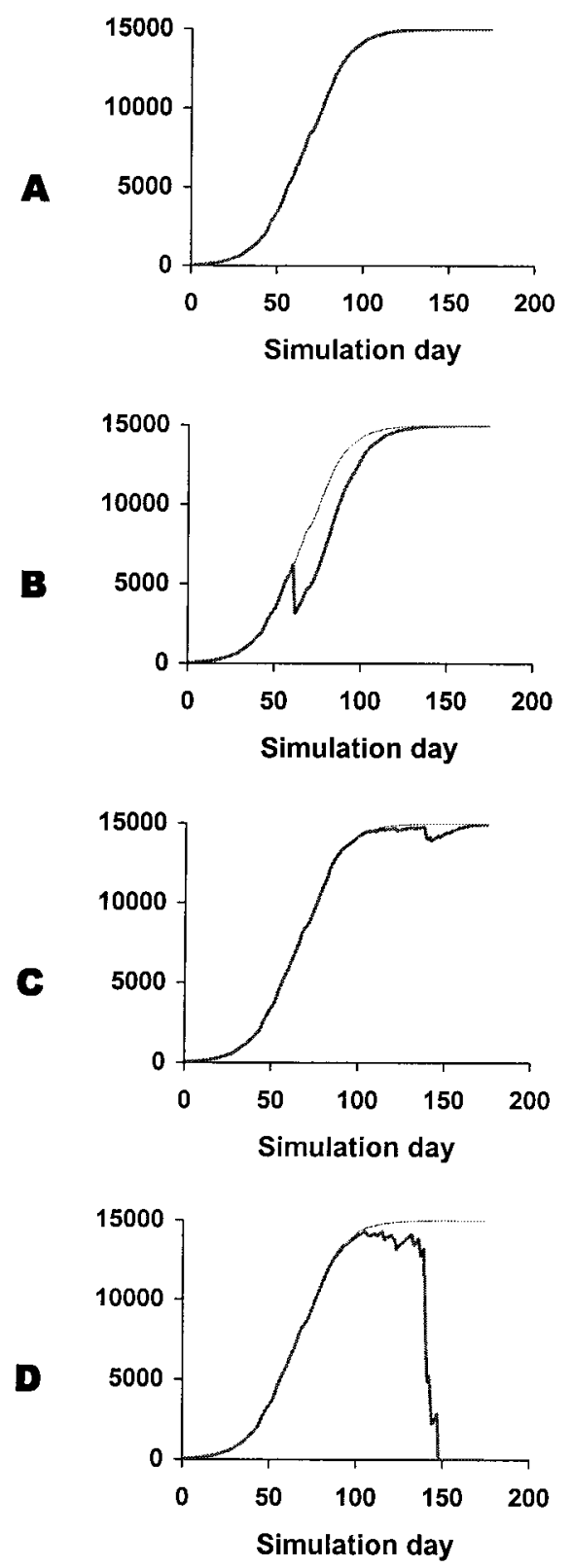

NEW GROWING POINTS PER DAY
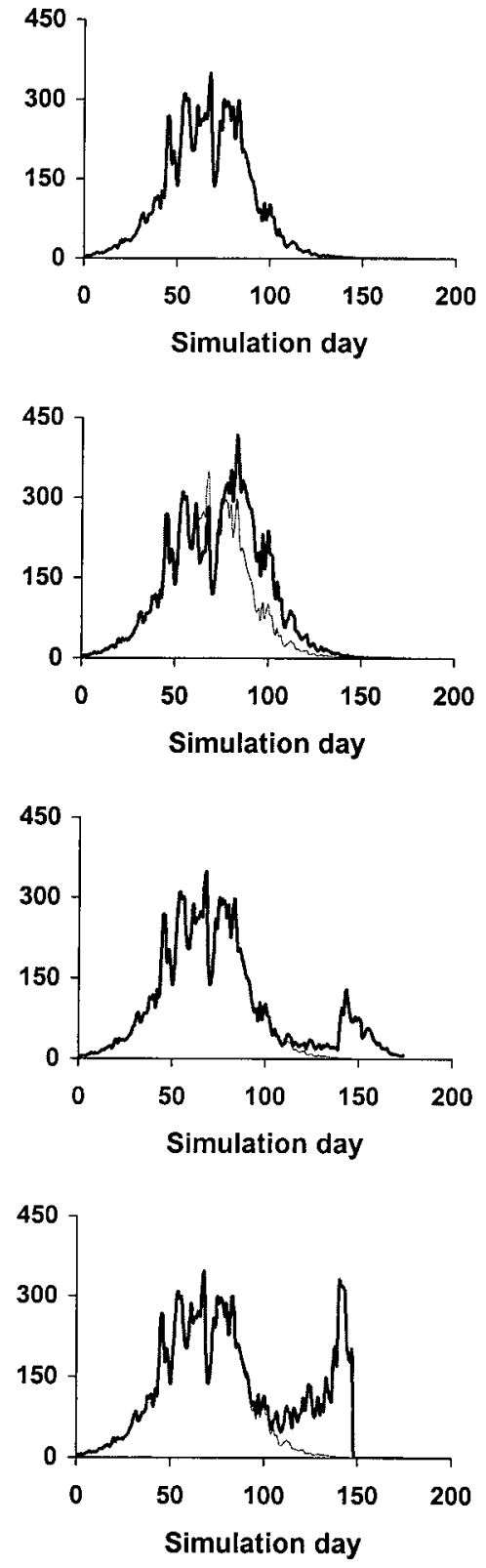

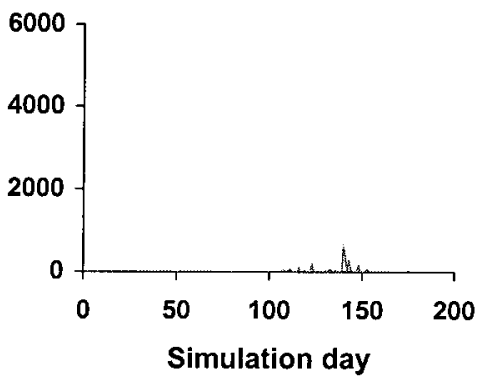

NEWLY INFECTIVE GROWING POINTS
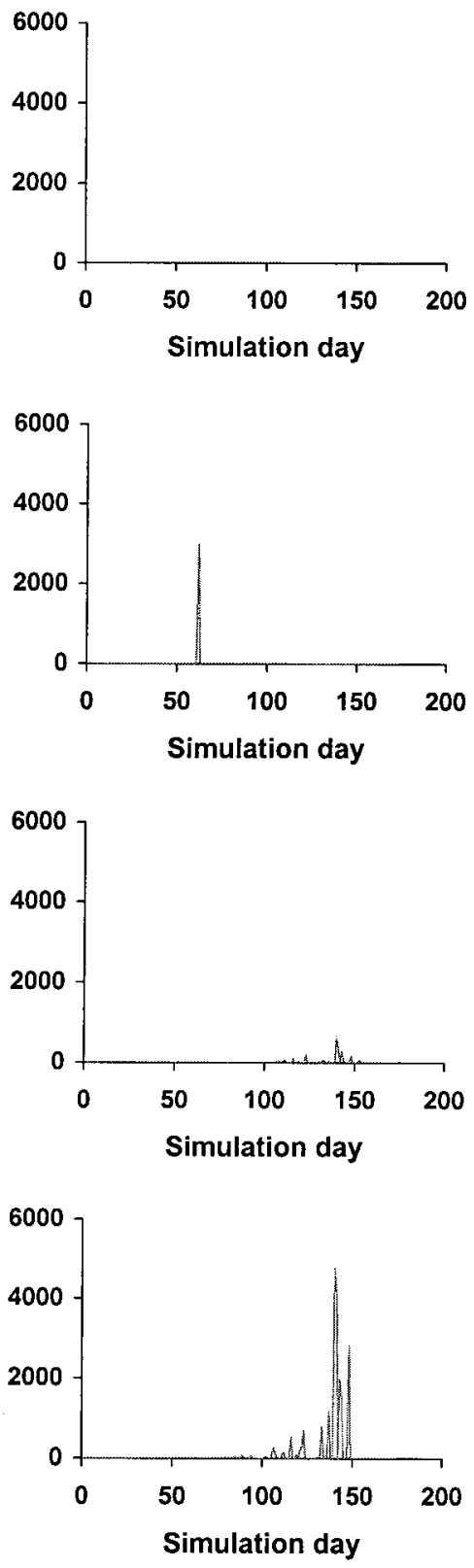

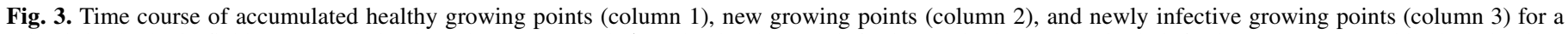

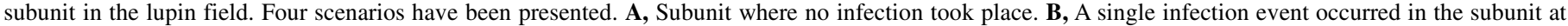

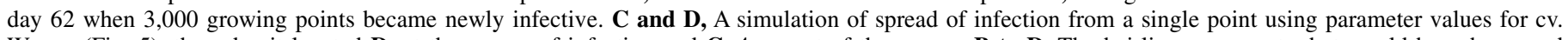

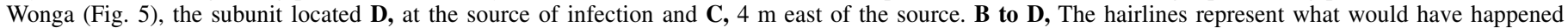
without any infection as shown in scenario $\mathbf{A}$. 


\section{Observation}

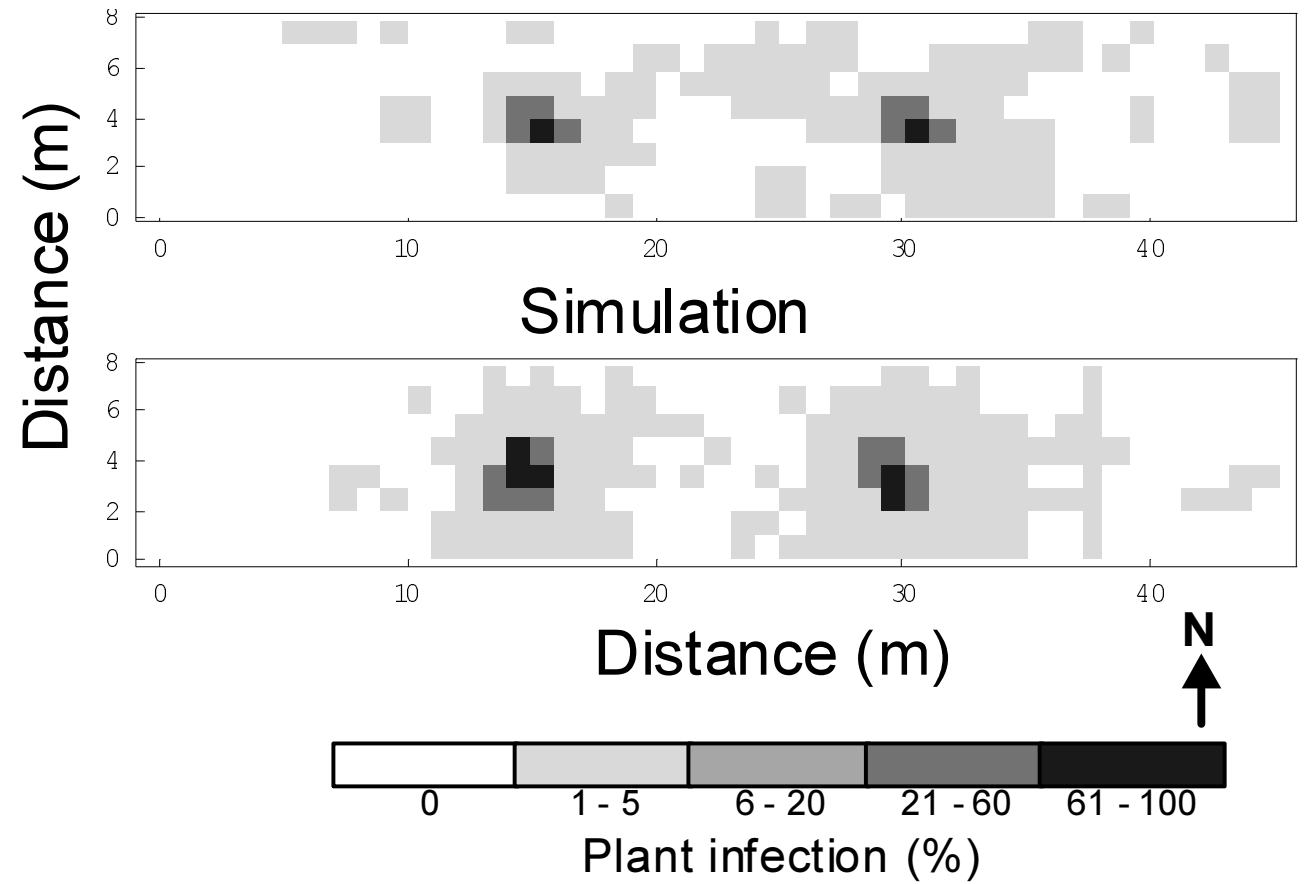

Fig. 4. Map of observed and simulated development of anthracnose (Colletotrichum gloeosporioides) in lupin cv. Myallie in a 45- $\times$ 8-m field during the 1998 growing season at Geraldton, Western Australia. Infection was initiated by two infected seeds in the field. Observation was made on 4 August (Fig. 6).

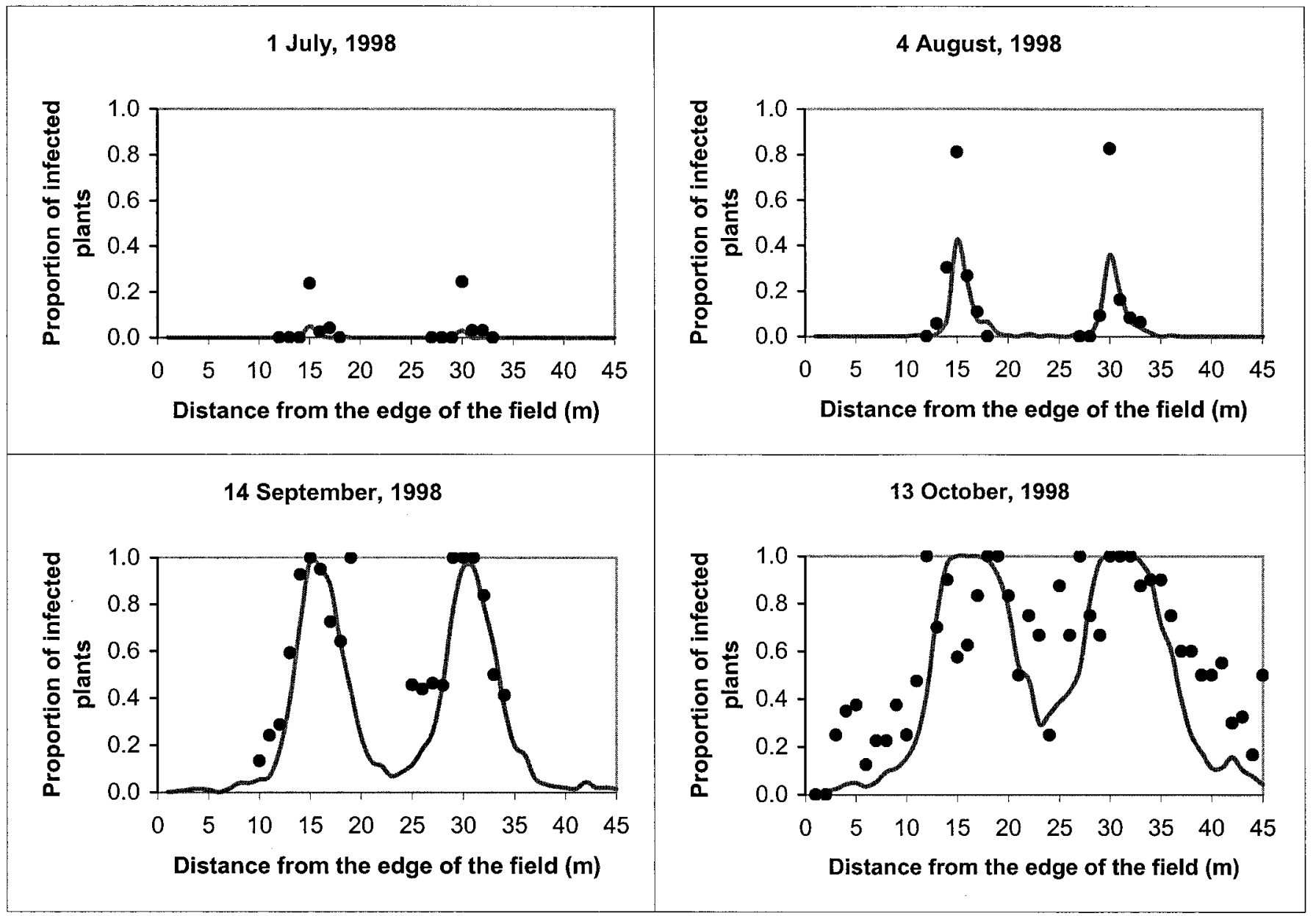

Fig. 5. Simulated (line) and observed (filled circle) incidence of anthracnose (Colletotrichum gloeosporioides) in lupin cv. Wonga at four times of measurement during the 1998 growing season. 
calibrated by fitting the model to field observations of anthracnose incidence during early disease development in the field.

The model is driven by the hourly weather data using air temperature, rainfall, wind speed, wind direction, and standard deviation of the wind direction (Table 4). Sizes of the field and subunits, density of the crop plants, and locations of infected seed are all initialization variables. We have used a subunit size of $1 \mathrm{~m}^{2}$ based on a sensitivity analysis, which indicated insensitivity to further reduction in size. As the model runs, it keeps continuous track of the number of healthy, infective (sporulating), and latent growing points in each subunit.

Several summary statistics can be derived from these base values. Two summary statistics are reported here. The first is percent loss or reduction in healthy growing points relative to an uninfected reference subunit $\left(F_{P h t / P h t X}\right)$ as shown in equation 8 :

$$
F_{P h t / P h t X}=\left[1-\left(P_{h t} / P_{h t X}\right)\right] 100
$$

where $P_{h t}$ is the number of healthy growing points in the subunit at time $t$ and $P_{h t X}$ is the number of healthy growing points that would have been present in a subunit where there was no disease. This value is simulated in the model in parallel with the simulations of the potentially diseased subunits that make up the field.

The second summary statistic is proportion of infected plants $\left(F_{\text {Nit/Nt }}\right)$ :

$$
F_{N i t / N t}=N-N(1-1 / N)^{P_{i t}}
$$

where $P_{i t}$ is the number of infective growing points in the subunit and $N$ is the number of plants per subunit, both at time $t$.

Model testing. The model was tested with data from a field experiment in which spread of anthracnose from known source plants was measured. The experiment was conducted in 1998 in Geraldton $\left(28.51^{\circ} \mathrm{S}\right.$ and $\left.114.75^{\circ} \mathrm{E}\right)$, Western Australia. The experiment was designed to assess yield loss due to anthracnose in two cultivars of narrow-leafed lupins, L. angustifolius (cvs. Wonga and Myallie) and one albus lupin, L. albus (cv. Kiev Mutant). On a relative anthracnose resistance scale ranging from 1 to $9, \mathrm{cv}$. Wonga ranks 7 (resistant), cv. Myallie ranks 3 (susceptible), and cv. Kiev Mutant ranks 1 (extremely susceptible) (5). Plots were $45 \times 8 \mathrm{~m}$ on $20 \mathrm{~cm}$ row spacing with a seeding density of approximately 40 plants per $\mathrm{m}^{2}$. An $8-\mathrm{m}$ buffer plot, sown to canola (Brassica napus), was maintained around each plot. Four replicate plots of each cultivar were sown on 20 May. Infection sources were initiated on 18 June (2-leaf stage) in each plot by transplanting two artificially anthracnose-infected seedlings of cv. Kiev Mutant per plot. These infected plants were located at 15 and $30 \mathrm{~m}$ along the center line, running the length of each plot.

Disease incidence was assessed by visual inspection for the presence of characteristic anthracnose lesions on plants on a transect along the center line of each plot on 1 July, 4 August, 14 September, and 13 October. On 1 July and 4 August, assessment was done on all plants up to $3 \mathrm{~m}$ on each side of both infection sources (15 and $30 \mathrm{~m}$ along the center of the plot). On 14 September, disease incidence was assessed on all plants up to $5 \mathrm{~m}$ on each side of the infection sources. For the final assessment date, data were collected along an entire 45-m transect of the plot, and a

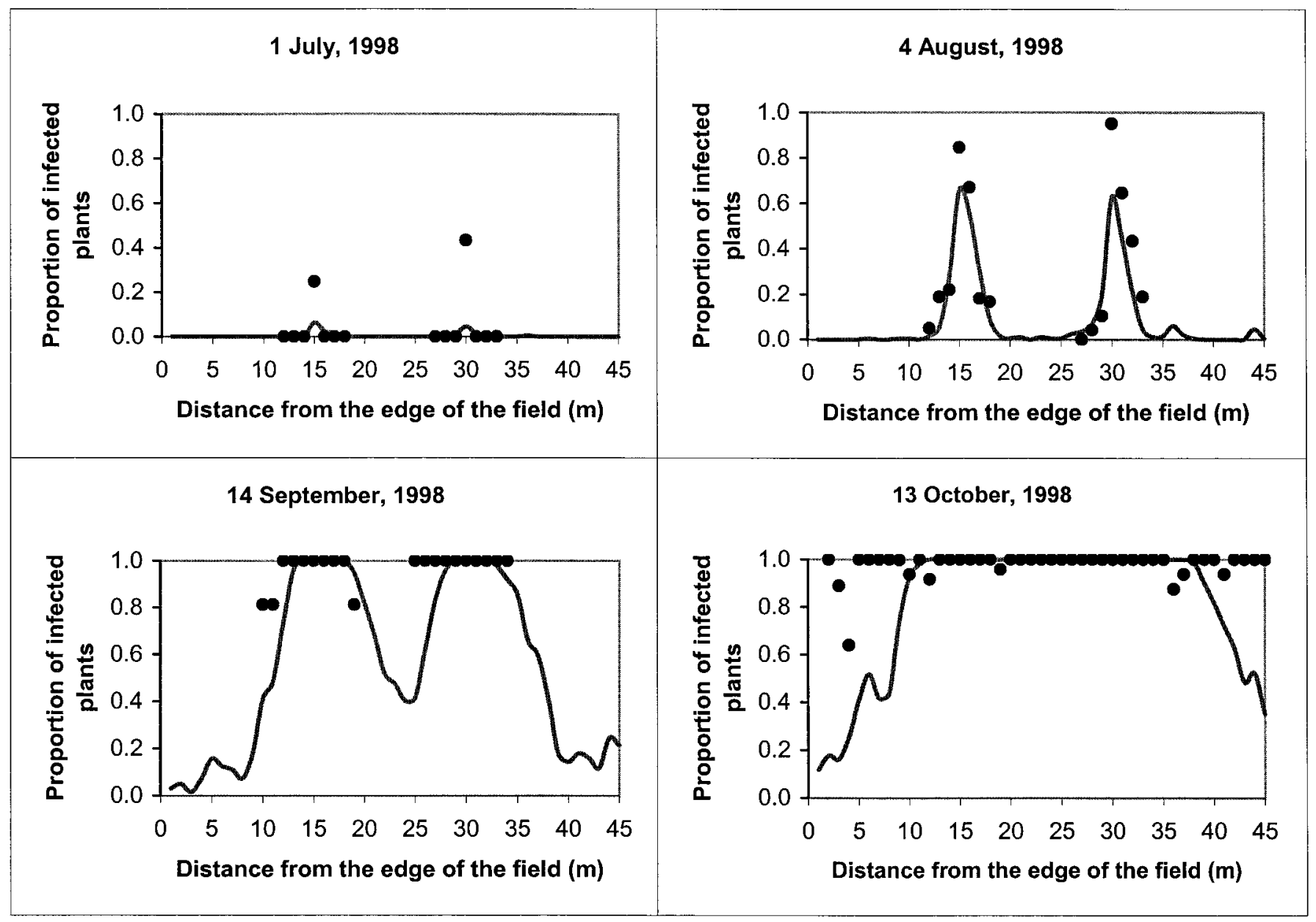

Fig. 6. Simulated (line) and observed (filled circle) incidence of anthracnose (Colletotrichum gloeosporioides) in lupin cv. Myallie at four times of measurement during the 1998 growing season. 
single plant nearest every $30-\mathrm{cm}$ interval was sampled. The information from these transects provided a detailed quantitative basis for comparison with model simulations but it was limited to assessment of spread in one dimension only.

To assess spread of anthracnose in two dimensions, incidence of anthracnose was estimated in $1-\mathrm{m}^{2}$ subunits of selected plots. Marker pegs were placed at 1-m intervals around the border of each of the four plots where cv. Myallie was grown. The number of anthracnose-infected plants was estimated on 4 August by visual rating in all of the subunits. This procedure was very approximate but has been useful for semiquantitative assessment of the pattern of spread of disease in two dimensions.

For the duration of the experiment, total rainfall (tipping bucket rain gauge, Model TB3; Hydrological Services Pty Ltd., Australia), average air temperature (RTD 3 wire PT100 type B TWA 6312; MTL Instruments, Australia), average and maximum wind speed (Met-one 014A wind speed sensor; Campbell Scientific, Logan, UT), and average and standard deviation of wind direction (Met-one 024A wind speed sensor; Campbell Scientific) were automatically logged every hour (Datataker DT50-series 2 datalogger; Data Electronics, Australia). This automatic weather station was placed directly beside the experimental site.

For a comparison with the experimental results, the model was initialized with the same start and end dates (20 May and 10 November), field size $(45 \times 8 \mathrm{~m})$, and plant density $\left(40\right.$ plants per $\left.\mathrm{m}^{2}\right)$ as the experiment. The model was run with the recorded weather data. On the date of initial infection in the experiment, one infective growing point was added to each of the two subunits corresponding to the points of initial infection in the field. The model was run four times, with no wrapping option, for each cultivar so that the mean of the model runs would be comparable in both magnitude and variability with the experimental data. The model iterates on a 1-h time step and the outputs were delivered on a daily basis for all the individual subunits as well as the average of the whole field. The model's output of proportion of infected plants (equation 9) was compared with the experimental data in two ways. Firstly, a comparison was made with the spatial pattern of disease spread in the field recorded for cv. Myallie on 4 August. This comparison included all 360 subunits of the field. Secondly, a comparison was made with the measured temporal pattern of anthracnose development in all three cultivars. This was done for the four dates when measurements were made along the central transect in the field, using model output for the $1-\mathrm{m}^{2}$ subunits located along the transect.

Simulated experimentation with the model. As mentioned earlier, the level of anthracnose infection in a crop is affected by several factors, particularly seasonal rainfall, level of introduced infection (level of seed infection), and the resistance of the cultivar used. Of particular importance to the farmers is how rainfall and cultivar interact with the level of seed infection. In order to examine this relationship, the model was used to simulate the effects of anthracnose at two locations in different rainfall environments in Western Australia, Geraldton (high rainfall, annual average $450 \mathrm{~mm}$ ) and Merredin (low rainfall, annual average $325 \mathrm{~mm}$ ). Two lupin cultivars, Wonga and Myallie, were tested using weather data from these sites for the 1998 growing season. Four of the levels of seed infection $(0.00015,0.0006,0.0025$, and $0.01 \%$ of the total seed) were the same for both locations, whereas

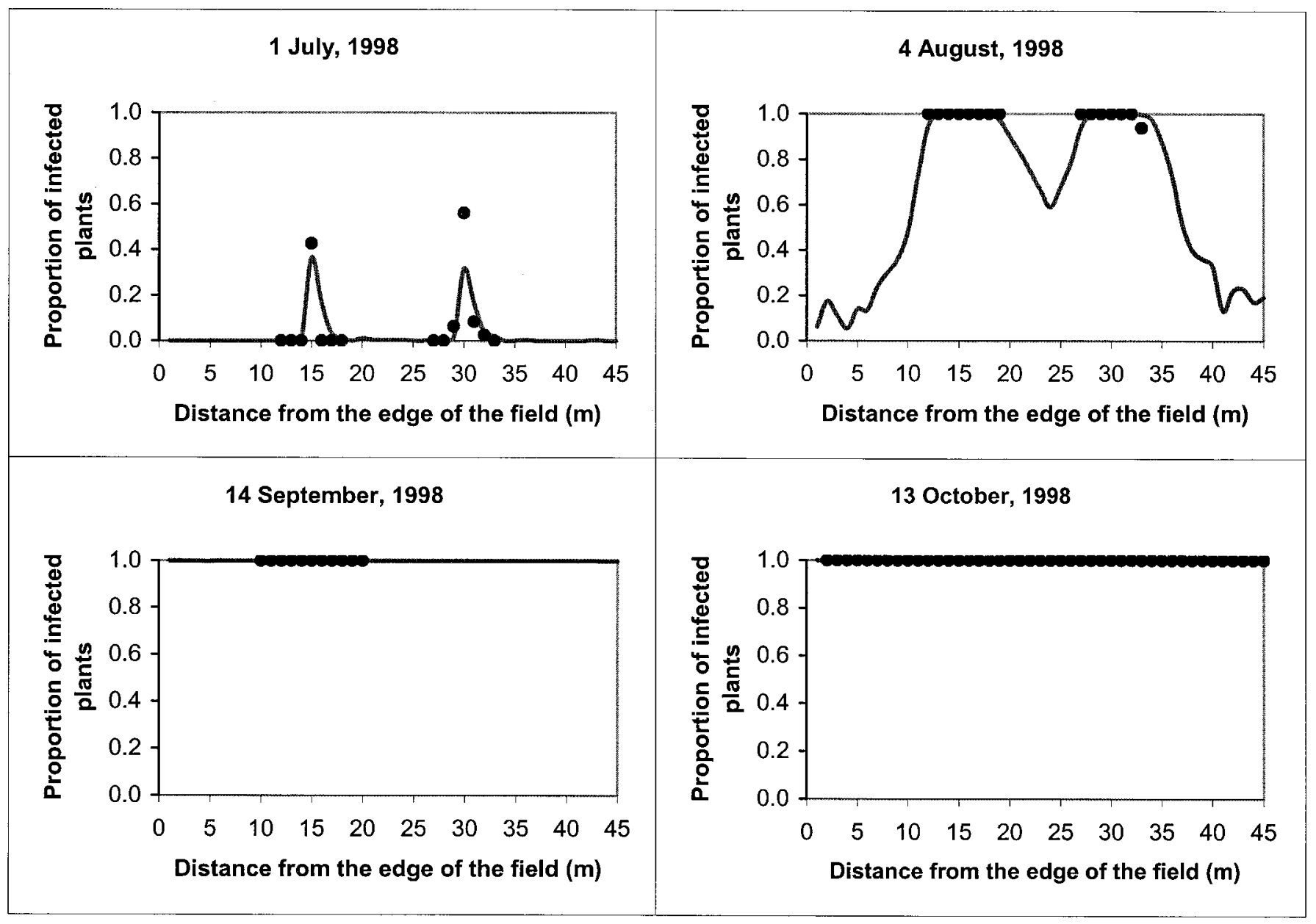

Fig. 7. Simulated (line) and observed (filled circle) incidence of anthracnose (Colletotrichum gloeosporioides) in lupin cv. Kiev Mutant at four times of measurement during the 1998 growing season. 
the fifth level was higher for Merredin (1\% of the total seed) than for Geraldton $(0.05 \%$ of the total seed). The model was run on a field of $200 \times 80 \mathrm{~m}$ with the spore wrapping option selected. Spore wrapping causes spores that would move outside of the simulated field to re-enter at the same point on the opposite side, thereby simulating infection moving into the field from neighboring areas with similar level of infection (Table 4). For Geraldton, the model settings were the same as those used in model testing. The start and end dates of the growing season for Merredin were set 15 days earlier than for Geraldton, in conformity with the actual growing season. The positions of infected seeds in the field were step-wise random. In the first treatment $(0.00015 \%$ seed infection), the one seed (at 40 seeds per $\mathrm{m}^{2}$ ) that was infected in the field was located at random. For the next treatment $(0.0006 \%$ seed infection), the location of the first infected seed was retained and the locations of the three additional seeds were selected randomly. This process was continued for the higher levels of seed infection. The same pattern of seed infection was used as far as possible for the two sites. The model's output of percent loss of growing points due to anthracnose (equation 8) was used to evaluate the effect of the different seed infection levels on two cultivars of lupin at two locations in Western Australia.

\section{RESULTS}

Growing point dynamics. Figure 3 illustrates development of growing points over a growing season in a subunit based on equations 1 and 2. With no disease, the pattern of accumulation of

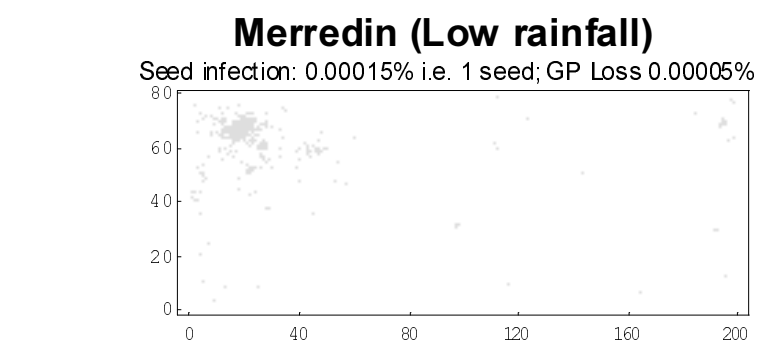

Seed infection: $0.0006 \%$ i. e. 4 seeds; GP Loss $0.0002 \%$
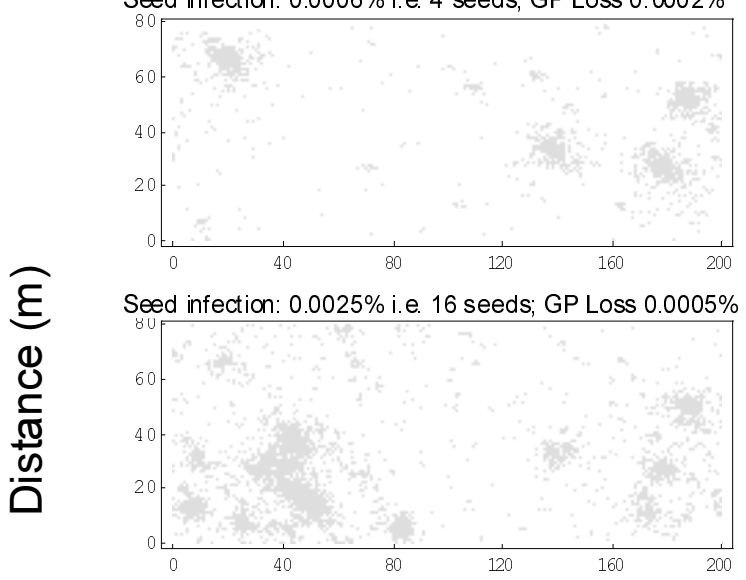

Seed infection: $0.01 \%$ i.e. 64 seeds; GP Loss $0.002 \%$

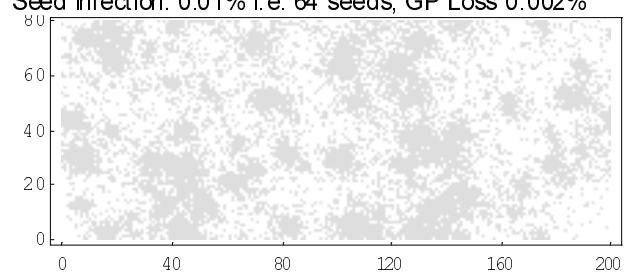

Seed infection: $1 \%$ i. e. 6400 seeds; GP Loss $0.22 \%$

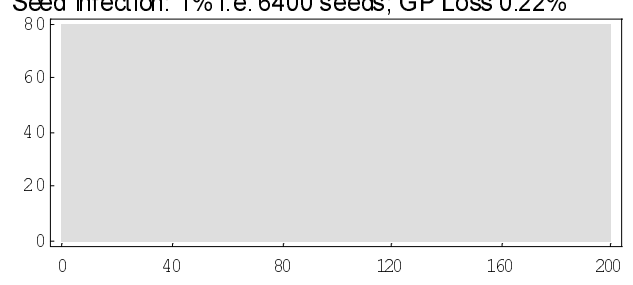

Geraldton (High rainfall)

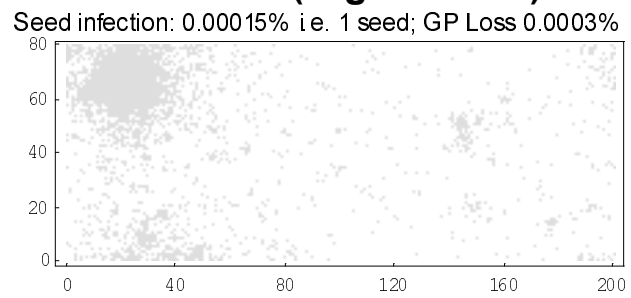

Seed infection: $0.0006 \%$ i.e. 4 seeds; GP Loss $0.0005 \%$

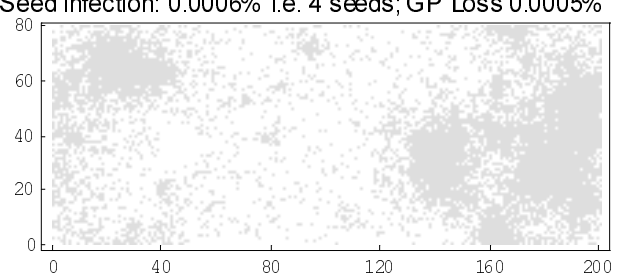

Seed infection: $0.0025 \%$ i.e. 16 seeds; GP Loss $0.004 \%$

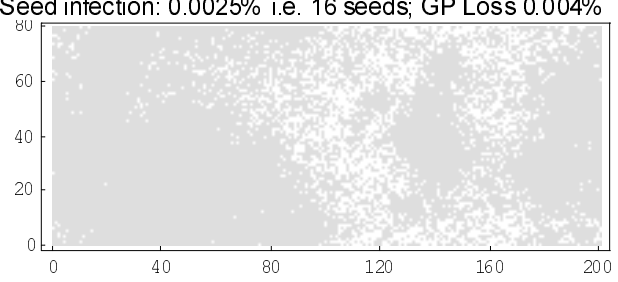

Seed infection: $0.01 \%$ i.e. 64 seeds; GP Loss $0.02 \%$

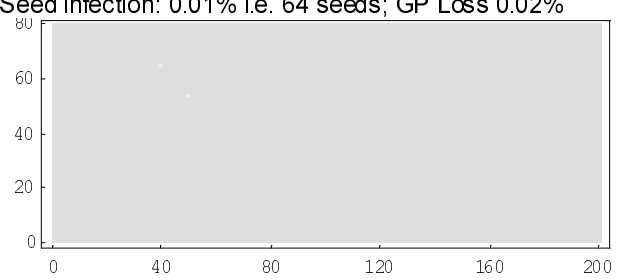

Seed infection: $0.05 \%$ i.e. 320 seds; GP Loss $0.24 \%$

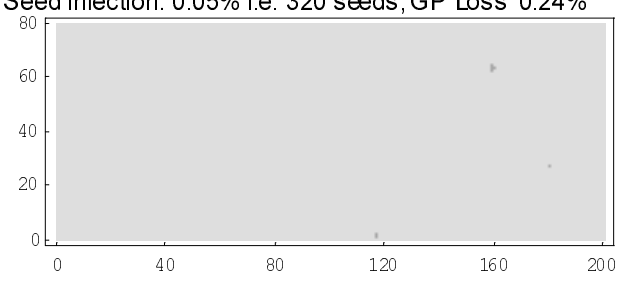

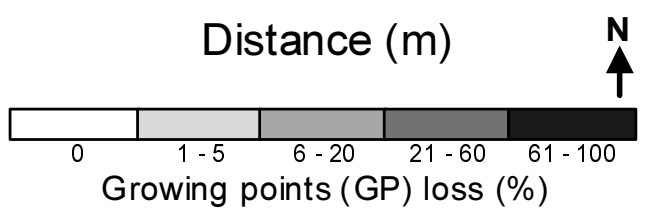

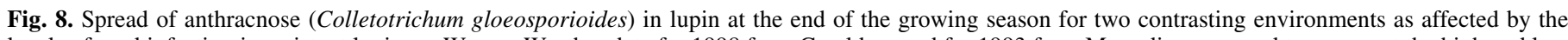

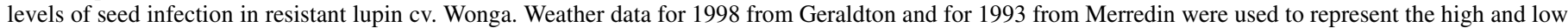
rainfall environments, respectively. Shading indicates percent loss of healthy growing points (GP) in each $1-\mathrm{m}^{2}$ subunit area of the field. 
growing points is shown in Figure 3A. If growing points in the subunit become infected at any stage, for example, $\mathrm{PI}_{\Delta t}=3,000$ on day 62 as shown in Figure 3B, the number of healthy growing points is immediately reduced. Development of growing points then resumes and eventually compensates for the loss. In a simulation of spread of infection from one infected seed in a $45-\times$ 8-m field, there was minor temporary loss of growing points followed by full compensation in the subunit $4 \mathrm{~m}$ north of the point of infection (Fig. 3C). In the same simulation, there was a complete loss of growing points in the subunit where initial infection had taken place (Fig. 3D).

Simulation versus observation-a comparison of spread in two dimensions. Simulated spread of anthracnose from two points of infection in a 45- $\times 8$-m field was compared with obser-

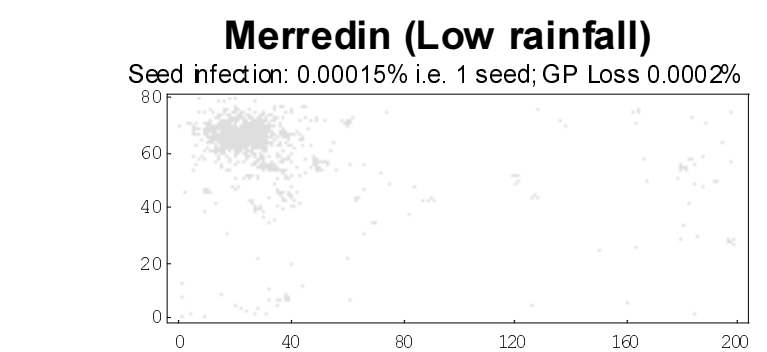

Seed infection: 1 in $0.0006 \%$ i.e. 4 seeds; GP Loss $0.001 \%$
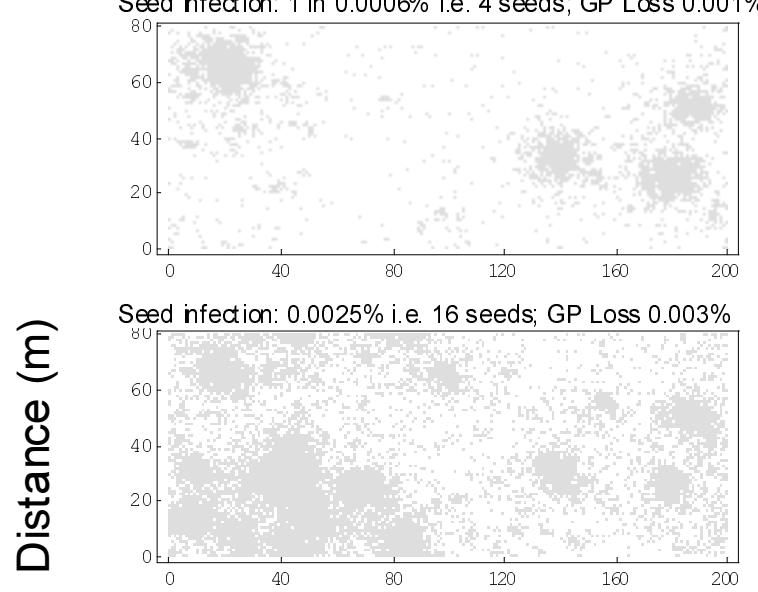

Seed infection: $0.01 \%$ i.e. 64 seeds; GP Loss $0.01 \%$

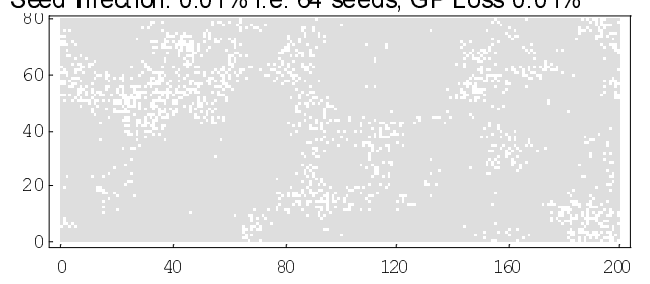

Seed infection: $1 \%$ i.e. 6400 seeds; GP Loss $3.87 \%$

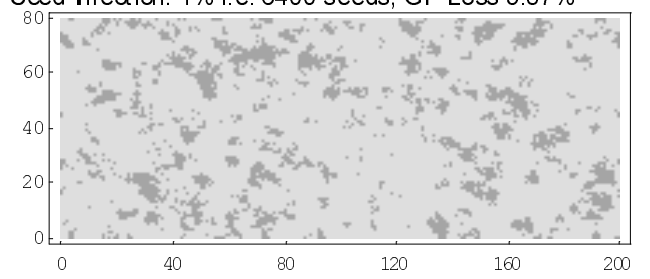

vation as shown in Figure 4. This comparison was semiquantitative as describe previously, and hence has not been analyzed in great detail. It appears that the model has overestimated total number of infections to some extent. Nevertheless, it is apparent that the pattern of spread produced by the model is similar to the pattern that occurred in the field.

Simulation versus observation-a comparison of spread along a transect. Disease incidence simulated by the model was compared with experimental data at four different times of measurement during the growing season for cvs. Wonga (Fig. 5), Myallie (Fig. 6), and Kiev Mutant (Fig. 7). Actual field observation showed cv. Kiev Mutant to have the highest level of infection followed by cv. Myallie and cv. Wonga. The calibrated model successfully simulated these cultivar differences. At all four times

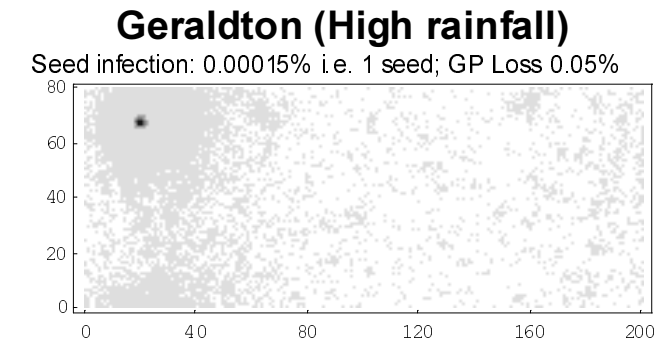

Seed infection: $0.0006 \%$ i.e. 4 seds / GP Loss $0.34 \%$

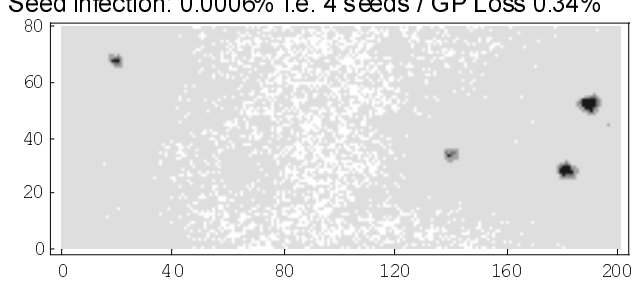

Seed infection: $0.0025 \%$ i.e. 16 seeds; GP Loss $202 \%$

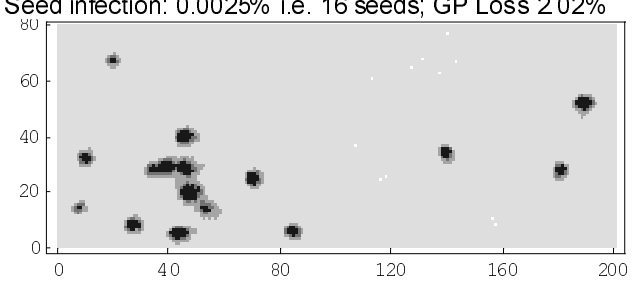

Seed infection: $0.01 \%$ i.e. 64 seeds; GP Loss $9.83 \%$

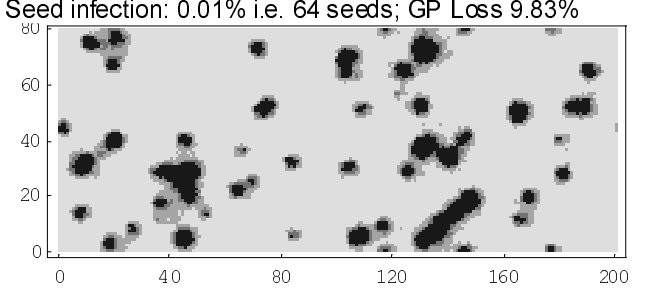

Seed infection: 0.05 i.e. 320 seeds; GP Loss $87.26 \%$

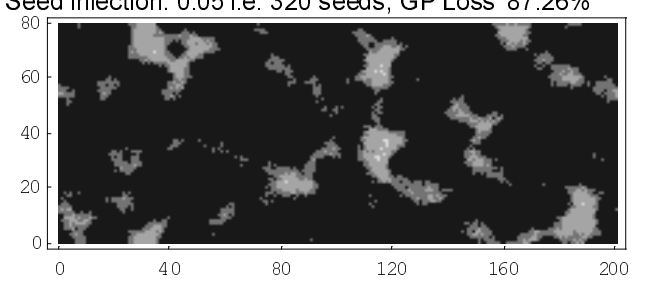

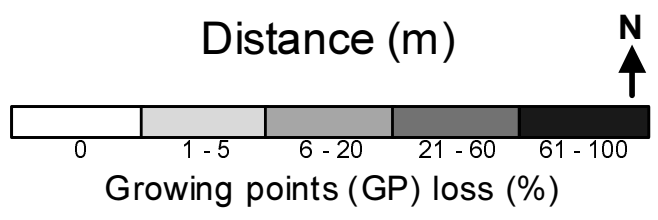

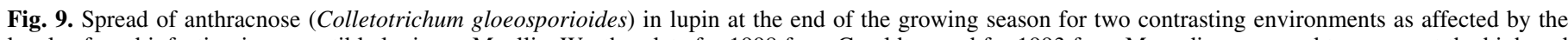

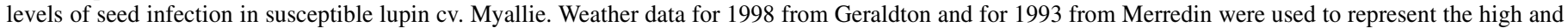
low rainfall environments, respectively. Shading indicates percent loss of healthy growing points (GP) in each $1-\mathrm{m}^{2}$ subunit area of the field. 
of observation, the model's prediction for cv. Kiev Mutant was very close to that measured in the field experiment. At the first two times (1 July and 4 August), the model underestimated incidence of disease for cvs. Wonga and Myallie at the points of infection. For 14 September, the prediction was close to the observation for both cultivars. The model largely captured the trend of spread of the disease along the entire plot for the 13 October observations, however, it tended to underestimate level of infection toward the edges of the plot.

Spread of lupin anthracnose: regional and cultivar factors. Using the model, an experiment was simulated to estimate how regional and cultivar factors and level of seed infection contribute to spread of the disease. The results showed that epidemics would be much more severe where rainfall was high, but that the scale of damage would depend on the crop cultivar and the level of seed infection. For resistant cv. Wonga, in the worst case tested, the predicted reduction of healthy growing points was only $0.24 \%$. This result was obtained for Geraldton, the high rainfall area, with a high level of infection in the seed sown, $0.05 \%$ (Fig. 8). In contrast, $87 \%$ loss of growing points was predicted for susceptible cv. Myallie, grown in the same region with the same level of seed infection (Fig. 9). In high rainfall conditions (Geraldton), the model showed that cv. Myallie lost approximately $15 \%$ of healthy growing points with an initial level of seed infection of $0.01 \%$. In the low rainfall environment (Merredin), a similar loss of growing points did not occur even with a very high level (1\%) of seed infection. With $0.01 \%$ infected seed in the low rainfall environment, cv. Myallie showed an estimated loss of healthy growing points of far less than $1 \%$.

\section{DISCUSSION}

We have developed a spatiotemporal model to simulate the spread of anthracnose in a lupin field by simultaneously simulating four processes. These are the growing point dynamics of lupin plants, the dynamics of spore production of Colletotrichum gloeosporioides (Penz.) in lupin cultivars that differ in their resistance, dispersal of spores (adapted from the function of Shaw [35] and $\mathrm{Xu}$ and Ridout [46]), and deposition of spores on the host. Most of the currently grown cultivars of narrow-leafed lupin have an indeterminate growth habitat (10). This means, as in some other systems $(18,19,34)$, that population or yield compensation is commonly observed in response to stress, as emphasized by Madden et al. (26). Our representation of growing point dynamics, in a simplified way, captures this flexibility. We have used the same growing point dynamics for all of the lupin cultivars that presented here. By changing two additional parameters, maximum number of growing points $\left(P_{h m}\right)$ and growing point replication rate $\left(R_{P h}\right)$, other lupin morphologies could be simulated.

The difference between cultivars in the simulations presented is due only to the value of the parameter $S_{p i}$ (equation 3), which is the rate of spore production per sporulating growing point. The actual number of spores produced by a focus depends on a number of factors such as the lesion size and age (42). Our model simplifies this relationship to a linear function of $S_{p i}$. This simplified relationship adequately reproduced the cultivar differences observed in the field experiment (Figs. 5 to 7).

This model can be used as a predictive tool to estimate crop damage caused by anthracnose in different cultivars with known levels of resistance, with a given level of seed infection in different climatic environments. In Western Australia, after the recent arrival of anthracnose, there has been a qualitative expectation that anthracnose is a more serious threat to production of lupins in high rainfall environments than in low rainfall environments. The model produces a quantified estimate of this difference and has assisted farm managers to assess the risk of losses in different cultivars. For example, in the high rainfall area, susceptible cultivars should only be used if levels of seed infection are known to be below $0.01 \%$ (Fig. 8). On the other hand, unless the seed infection level is $>1 \%$, cultivar choice is unrestricted in the low rainfall regions. This information is valuable when farm managers need to interpret seed testing results for level of anthracnose infection. In the future, the model could potentially be applied to decisions relating to factors such as time of sowing and time and frequency of fungicide application.

\section{ACKNOWLEDGMENTS}

This research was supported by the Grains Research and Development Corporation (GRDC), Western Australia. We thank several staff of Department of Agriculture-Western Australia for help, especially, M. Dracup for suggestions and information relating to lupin growth and development, K. Adcock for collection and processing of data, and F. Gianoli for assistance with programming.

\section{LITERATURE CITED}

1. Aylor, D. E. 1998. The areobiology of apple scab. Plant Dis. 82:838-849.

2. Aylor, D. E. 1999. Biophysical scaling and passive dispersal of fungus spores: Relationship to integrated pest management strategies. Agric. For. Meteorol. 97:275-292.

3. Aylor, D. E., and Ferrandino, F. J. 1989. Temporal and spatial development of bean rust epidemics initialed from an inoculated line source. Phytopathology 79:146-151.

4. Aylor, D. E., Taylor, G. S., and Raynor, G. S. 1982. Long-range transport of tobacco blue mold spores. Agric. Meteorol. 27:217-232.

5. Crop Variety Sowing Guide (CVSG). 1999. The Crop Variety Sowing Guide 2000. Bulletin 4372. Agriculture Western Australia, 3 Baron-Hay Court, South Perth.

6. Davies, C. L., Turner, D. W., and Dracup, M. 2000. Yellow lupin (Lupinus luteus) tolerates waterlogging better than narrow-leafed lupin (L. angustifolius). III. Comparison under field conditions. Aust. J. Agric. Res. 51:721-727.

7. Dick, M. A. 1994. Blight of Lupinus arboreus in New Zealand. N.Z. J. For. Sci. 24:51-68.

8. Diggle, A. J., Thackray, D. J., Yang, H., and Sweetingham, M. W. 1997. A simulation model for the spread of lupin anthracnose. Page 246 in: Abstracts of Papers. Biennial APPS Conf., 11th. Australian Plant Pathology Society, Perth.

9. Dracup, M., and Kirby, E. J. M. 1993. Patterns of growth and development of leaves and internodes of narrow-leafed lupin. Field Crops Res. 34:209-225.

10. Dracup, M., and Kirby, E. J. M. 1996. Lupin Development Guide. University of Western Australia Press, Nedlands, Western Australia.

11. Dracup, M., and Kirby, E. J. M. 1996. Pod and seed growth and development of narrow-leafed lupin in a water limited Mediterranean-type environment. Field Crops Res. 48:209-222.

12. Dracup, M., Reader, M. A., and Palta, J. A. 1998. Variation in yield of narrow-leafed lupin caused by terminal drought. Aust. J. Agric. Res. 49:799-810.

13. Dracup, M., Thomson, B., Reader, M., Kirby, E. J. M., Shield, I., and Leach, J. 1998. Daylength responses, flowering time, and seed filling in lupins. Aust. J. Agric. Res. 49:1049-1055.

14. Estrada, A. B., Jeffries, P., and Dodd, J. C. 1996. Field evaluation of a predictive model to control anthracnose disease of mango in the Philippines. Plant Pathol. 45:294-301.

15. France, J., and Thornley, J. H. M. 1984. Mathematical Models in Agriculture. Butterworths, London.

16. Gibson, G. J., and Austin, E. J. 1996. Fitting and testing spatio-temporal stochastic models with application in plant epidemiology. Plant Pathol. 45:172-184.

17. Gondran, J., and Pacault, D. 1997. L'anthracnose du lupin blanc. Phytoma La Detense des Vegetaux. 494:28-31.

18. Hirst, J. M., Hide, G. A., Stedman, O. J., and Griffith, R. L. 1973. Yield compensation in gappy potato crops and, methods to measure effects of fungi pathogenic on seed tubers. Ann. Appl. Biol. 73:143-150.

19. Hughes, G., and Madden, L. V. 1997. The determination of yield losses with aggregated patterns of diseased or missing plants. Pages 156-160 in: Exercises in Plant Disease Epidemiology. L. J. Francl and D. Neher, eds. The American Phytopathological Society, St. Paul, MN.

20. Huyghe, C. 1997. White lupin (Lupinus albus L.). Field Crops Res. 53:147-160.

21. Jeger, M. J. 1999. Improved understanding of dispersal in crop pest and disease management: Current status and future directions. Agric. For. Meteorol. 97:331-349. 
22. Jeger, M. J., and Thresh, J. M. 1992. Modelling spread of cocoa swollen shoot disease in pandemically-diseased areas. J. Appl. Ecol. 30:187-196.

23. Koch, S. H. 1996. Colletotrichum spp. on dry beans and lupins in South Africa. Ph.D. thesis. University of Pretoria, South Africa.

24. Lindbeck, K. D., Murray, G. M., Nikandrow, A., and Dominiak, B. C. 1998. Survey of anthracnose caused by Colletotrichum gloeosporioides in crop lupins (Lupinus angustifolius, L. albus) and ornamental lupins (L. polyphyllus) in New South Wales. Aust. Plant Pathol. 27:259-262.

25. Madden, L. V., and Hughes, G. 1995. Plant disease incidence: Distributions, heterogeneity, and temporal analysis. Annu. Rev. Phytopathol. 33:529-564.

26. Madden, L. V., Hughes, G., and Irwin, M. E. 2000. Coupling diseaseprogress-curve and time-of-infection functions for predicting yield loss of crops. Phytopathology 90:788-800.

27. Minogue, K. P., and Fry, W. E. 1983. Models for the spread of disease: Model description. Phytopathology 73:1168-1173.

28. Minogue, K. P., and Fry, W. E. 1983. Models for the spread of plant disease: Some experimental results. Phytopathology 73:1173-1176.

29. Mollison, D. 1977. Spatial contact models for ecological and epidemic spread. J. R. Stat. Soc. Ser. B 39:283-326.

30. Monroe, J. S., Santini, J. B., and Latin, R. 1997. A model defining the relationship between temperature and leaf wetness duration, and infection of watermelon by Colletotrichum orbiculare. Plant Dis. 81:739-742.

31. Paulitz, T. C., Atlin, G., and Gray, A. B. 1995. First report of Colletotrichum gloeosporioides on lupine in Canada. Plant Dis. 79:319.

32. Peredo, H. L., and Valenzucla, F. E. 1988. New records of pathogenic fungi of forest plants in Chile. Boltin Micologico 3:249-252.

33. Read, P. J., Dickens, J. S. W., and O'Neill, T. M. 1996. Occurrence of anthracnose (Colletotrichum acutatum) on ornamental lupin in the United Kingdom. Plant Pathol. 45:245-248.

34. Scott, G. E., and Rosenkranz, E. E. 1981. Effect of field distribution of maize dwarf mosaic-diseased corn plants on yield. Plant Dis. 65:802803.

35. Shaw, M. W. 1996. Simulating dispersal of fungi spores by wind, and resulting patterns. Pages 165-172 in: Aspects of Applied Biology, Vol. 46, Modelling in Applied Biology: Spatial Aspects. The Association of
Applied Biologists, Wellesbourne, Warwick, England.

36. Shea, G. 1999. Managing lupin anthracnose. J. Agric. West. Aust. 40:24-30.

37. Shivas, R. G., McClements, J. L., and Sweetingham, M. W. 1998. Vegetative compatibility amongst isolates of Colletotrichum causing lupin anthracnose. Aust. Plant Pathol. 27:269-273.

38. Smyth, G. K., Chakraborty, S., Clark, R. G., and Pettitt, N. 1992. A stochastic model for anthracnose development in Stylosanthes scabra. Phytopathology 82:1267-1272.

39. Sweetingham, M. W., Cowling, W. A., Buirchell, B. J., Brown, A. G. P., and Shivas, R. G. 1995. Anthracnose of lupins in Western Australia. Aust. Plant Pathol. 24:271.

40. Sweetingham, M. W., Jones, R. A. C., and Brown, A. G. P. 1998. Diseases and pests. Pages 263-290 in: Lupins as Crop Plants: Biology, Production and Utilization. J. S. Gladstones, C. Atkins, and J. Hamblin, eds. CAB International, UK.

41. Timmer, L. W., and Zitko, S. E. 1996. Evaluation of a model for prediction of postbloom fruit drop of citrus. Plant Dis. 80:380-383.

42. van der Plank, J. E. 1975. Principles of Plant Infection. Academic Press, New York.

43. van Heemst, H. D. J. 1986. Physiological principles. Pages 13-26 in: Modelling Agricultural Production: Weather, Soils and Crops. H. van Keulen and J. Wolf, eds. PUDOC, Wageningen, the Netherlands.

44. Weimer, J. L. 1943. Anthracnose of lupines. Phytopathology 33:249-252.

45. Wilson, P. A., and Chakraborty, S. 1998. The virtual plant: A new tool for the study and management of plant diseases. Crop Prot. 17:231-239.

46. Xu, X.-M., and Ridout, M. S. 1998. Effects of initial epidemic conditions, sporulation rate, and spore dispersal gradient on the spatio-temporal dynamics of plant disease epidemics. Phytopathology 88:1000-1012.

47. Yang, H. A., and Sweetingham, M. W. 1998. The taxonomy of Colletotrichum isolates associated with lupin anthracnose. Aust. J. Agric. Res. 49:1213-1223

48. Yang, X. S., Madden, L. V., and Brazee, R. D. 1991. Application of diffusion equation for modelling splash dispersal of point-source pathogens. New Phytol. 118:295-301.

49. Zadoks, J. C., and van den Bosch, F. 1994. On the spread of plant disease: A theory on foci. Annu. Rev. Phytopathol. 32:503-521. 